\title{
RYE AND OAT CRISPBREAD IMPROVEMENT WITH BIOLOGICALLY ACTIVE SUBSTANCES FROM PLANT BY-PRODUCTS
}

\author{
Daiga Konrade, Dace Klava \\ Latvia University of Life Sciences and Technologies, Latvia \\ daigakonrade@gmail.com
}

\begin{abstract}
Vegetable processing in food industry results in significant number of by-products - peel, mark, bark, seeds still rich in bioactive compounds. The objective of this study was to investigate the stability of total phenolic content (TPC) and antioxidant activity after high temperature short time (HTST) extrusion cooking of a rye and oat- based matrix with addition of apple, carrot and pumpkin by-product flour (BPF) in various amounts (5\%,10\%, 15\% and $20 \%)$. Extrusion was performed with co-rotating twin-screw extruder (compression ratio 8:1) at Ltd MILZU. The main drive of extruder was provided with a $7.5 \mathrm{HP}$ motor (400 V, 3 HP, 50 cycles). Temperatures for extrusion zones were 125 ${ }^{\circ} \mathrm{C} / 135^{\circ} \mathrm{C} / 145^{\circ} \mathrm{C}$. TPC was determined using the Folin Ciocalteu method. Antioxidant activity was evaluated by free radical 2, 2-diphenyl-1-picrylhydrazyl (DPPH) antioxidant scavenging activity. TPC in cereal-based crispbread was $62.03 \pm 0.15 \mathrm{mg} \mathrm{GAE} \mathrm{g}^{-1} \mathrm{DW}$ before extrusion and $37.73 \pm 1.96 \mathrm{mg} \mathrm{GAE} \mathrm{g}^{-1} \mathrm{DW}$ after extrusion. Addition $20 \%$ of apple BPF increased TPC in crispbread to $193.92 \pm$ 1.37, carrot BPF $171.36 \pm 6.97$ and pumpkin BPF to 195.09 $\pm 4.68 \mathrm{mg} \mathrm{GAE} \mathrm{g}^{-1} \mathrm{DW}$ after extrusion. Antioxidant activity of control (20\% oats, $80 \%$ rye flour blends) sample was $0.516 \pm 0.192 \mathrm{mg} \mathrm{TE} \mathrm{g}^{-1} \mathrm{DW}$ but in samples with addition of $20 \%$ by-products, it was significantly higher reaching $0.926 \pm 0.05 \mathrm{TE} \mathrm{g}^{-1} \mathrm{DW}$ in samples with pumpkin by-products after extrusion.
\end{abstract}

Key words: antioxidants, by-products, crispbread, extrusion, total phenolic content.

\section{Introduction}

Roughly one third of the food produced in the world for human consumption gets lost or is wasted. It constitutes approximately 1.3 billion tonnes per year. Around 100 million tonnes of food are wasted annually in the EU (Vaqué, 2015). If nothing is done, food waste could rise to over 120 million tonnes by 2020 (Turon et al., 2018). Global quantitative food losses and waste per year are roughly $30 \%$ for cereals; $40-50 \%$ for root crops, fruits and vegetables (Vaqué, 2015). The amount of food lost or wasted every year is equivalent to more than half of the world's annual cereals crop (2.3 billion tonnes in 2009/2010).

The vegetable and fruit processing industry produces such by-products as peel, mark, bark, seeds that can be used in the manufacture of other foods. They contain a lot of biologically valuable compounds, such as fibre, micro and macronutrients, organic acids. Food processing waste has the potential to be converted into useful products and utilized as supplements for the functional ingredient for consumers as a source of functional compounds.

Oats and rye are traditionally crops grown under Latvian conditions, which are valuable raw materials to produce many products, including crispbreads too.

The apple (Malus domestico) pomace is used as a substrate in several microbial processes for the production of organic acids, enzymes, and pigments (Figuerola \& Mar, 2005). Apple polyphenols are frequently cited as important contributors in different models of human chronic diseases (Elleuch et al., 2011). Apple pomace imparts nutritional benefits in the form of soluble dietary fibres, which are recognized for blood cholesterol-lowering functions (Paraman et al., 2015). The antioxidant activity of apples is rooted in their ability to donate phenolic hydrogens

Estimates of food waste in EU *(Stenmark et al., 2016)

Table 1

\begin{tabular}{|c|c|c|}
\hline Sector & $\begin{array}{c}\text { Food waste (million tonnes) with 95\% } \\
\text { CI** }\end{array}$ & $\begin{array}{c}\text { Food waste kg per Person with 95\% } \\
\text { CI** }\end{array}$ \\
\hline Primary production & $9.1 \pm 1.5$ & $18 \pm 3$ \\
\hline Processing & $16.9 \pm 12.7$ & $33 \pm 2$ \\
\hline Wholesale and retail & $4.6 \pm 1.2$ & $9 \pm 2$ \\
\hline Food service, catering & $10.5 \pm 1.5$ & $92 \pm 9$ \\
\hline Households & $46.5 \pm 4.4$ & $173 \pm 27$ \\
\hline Total food waste & $87.6 \pm 13.7$ & \\
\hline
\end{tabular}

*EU-28 2012 from this quantitative study. Includes food and inedible ingredients.

** Confidence interval. 
to lipid radicals, therefore generally considered to be more potent than as a chain-breaking antioxidant for inhibiting lipid peroxidation in food products thus prolonging their shelf life (Jiang et al., 2001).

The carrot (Daucus carota) pomace is a by-product obtained during carrot juice processing and rich source of $\beta$-carotene and contains thiamine, riboflavin and minerals (Kaur, Kaur, \& Ahluwalia, 2014). Carrot is a significant source of phytochemicals, including phenolic compounds and carotenoids (Arscott \& Tanumihardjo, 2010).

Pumpkin (Cucurbita pepo) peel is rich in pectin and is an excellent source of $\beta$-carotene, which the body converts into the important antioxidant of vitamin A. Pumpkin contains biologically active components such as polysaccharides, proteins and peptides, phenolic compounds, terpenoids and sterols. Pumpkin seeds are rich in carotenoids, including lutein, carotene, and including $\beta$-carotene too. The seed oil is rich in unsaturated fatty acids, as linoleic, oleic, and saturated as palmitic, and stearic acids. The oil is also rich in vitamin $\mathrm{E}$, including both $\mathrm{\gamma}$-tocopherol and $\alpha$-tocopherol (Mala, 2016). Pumpkin can also be processed into flour, which has a longer shelf-life.

One of the usages of the by-products might be their incorporation in the manufacture of extruded products. The production of foodstuffs by the extrusion method is a way to turn starchy products (grains, potatoes) into readily available and usable products such as breakfast cereals, pasta products, snack bars, chips.

The objective of this study was to investigate the stability of total phenolic content (TPC) and antioxidant activity after high temperature short time (HTST) extrusion cooking of a rye and oat- based matrix with addition of apple, carrot and pumpkin by-product flour (BPF) in various amounts $(5 \%, 10 \%$, $15 \%$ and $20 \%)$.

\section{Materials and Methods}

The study was realised at the scientific laboratories of the Faculty of Food Technology at Latvia University of Life Sciences and Technologies and in JSC MILZU.

For development of crispbread as raw materials 1880 type rye flour (JSC Dobeles dzirnavnieks), oat flour, apple pomace, seeds and peel, carrot pomace and peel and pumpkin peel and pomace were used.

By-products obtained from local juice producers were dried in a microwave - a vacuum dryer "MUSON-1" (Russia) according to the developed program. The necessary amount of microwave energy (magnetron minutes) was calculated according to the weight, moisture of by-products. Dried by-products were ground to a powder by the grinder FOSS KNIFITECTM 1095 (Germany) for 30 seconds each grind. After that they were sieved through $2 \mathrm{~mm}$ sieve. TPC content was determined in dried carrot, apple, pumpkin by-product flour, in rye and oat flour for crispbread production.

Control samples were prepared from rye flour, oat flour (80:20) and water 17\%, based on the recipe of LTD Milzu. Experimental samples were prepared with addition of apple, carrot and pumpkin by-product flour (BPF) $5 \%, 10 \%$ and $15 \%, 20 \%$ to dry ingredients of cereal, a part of cereal flour was replaced.

Samples were prepared with a co-rotating twinscrew extruder (compression ratio 8:1) at LTD MILZU. The main drive of extruder was provided with a 7.5 HP motor (400 V, 3 HP, 50 cycles). Temperatures for extrusion zones according to developed technologies at LTD Milzu were $125^{\circ} \mathrm{C} / 135^{\circ} \mathrm{C} / 145^{\circ} \mathrm{C}$.

Coded samples are displayed in Table 2.

The moisture content of selected material was determined with Memmert equipment Modell-100-800 (Germany) according to standard LVS EN ISO712:2010 A.

The total phenolic content of the extruded product extracts was determined according to the Folin-Ciocalteu spectrophotometric method with modifications. Extraction was performed by the method described by Tomsone and Kruma (Tomsone \& Kruma, 2017).

Antioxidant activity of the extruded product extracts was measured based on scavenging activity of the stable 2, 2-diphenyl-1-picrylhydraziyl (DPPH) radical. The radical scavenging activity was expressed as Trolox equivalent (TE) $100 \mathrm{~g}^{-1} \mathrm{DW}$ of extruded material.

All analysis was performed in triplicate, and results are presented as a mean value \pm standard deviation (SD). Statistically significant differences between results were calculated at the level of confidence $\alpha=0.05$.

The one-way analysis of variance was analysed by Microsoft Excel 2010.

\section{Results and Discussion}

Antioxidants are of twofold interest as for food scientists and health professionals and there has been a convergence of interest among researchers in these fields as the role of antioxidants in the diet and their impact on human health has come under attention (Mala, Sathiya, \& EKurian, 2016). Antioxidants defend against oxidative injury and are therefore believed to provide protection against various diseases - different types of cancer and coronary heart diseases (Uddin \& Ahmad, 1995).

Among the most valuable bioactive compounds in vegetable by-products peel, bark, mark seeds and cereals are the phenolic antioxidants (Awika, 2003).

Scientists Dar, Sharma and Kumar reported a significant decrease in total phenolic content during barley flour extrusion (Dar, Sharma, \& Kumar, 2014) 


\section{Composition of experimental samples}

\begin{tabular}{|l|l|}
\hline \multicolumn{1}{|c|}{ Sample } & \multicolumn{1}{c|}{ Composition } \\
\hline Control crispbread & Rye - 80\%, oats - 20\% \\
\hline ABF5 & $95 \%$ - Control crispbread, 5\% - ABF* \\
\hline ABF10 & $90 \%$ - Control crispbread, 10\% - ABF \\
\hline ABF15 & $85 \%$ - Control crispbread, 15\% - ABF \\
\hline ABF20 & $80 \%$ - Control crispbread, 20\% - ABF \\
\hline CBF5 & $95 \%$ - Control crispbread, 5\% - CBF** \\
\hline CBF10 & $90 \%$ - Control crispbread, 10\% - CBF \\
\hline CBF15 & $85 \%$ - Control crispbread, 15\% - CBF \\
\hline CBF20 & $80 \%$ - Control crispbread,20\% - CBF \\
\hline PBF5 & $95 \%$ - Control crispbread, 5\% - PBF*** \\
\hline PBF10 & $90 \%$ - Control crispbread, 10\% - PBF \\
\hline PBF15 & $85 \%$ - Control crispbread, 15\% - PBF \\
\hline PBF20 & $80 \%$ - Control crispbread,20\% - PBF \\
\hline
\end{tabular}

*ABF - apple by-product flour.

**CBF - carrot by-product.

$* * * \mathrm{PBF}-$ pumpkin by-product.

while others show an increase or no change for both phenols and antioxidant activity. Some reports also indicate that extrusion may partly depolymerize some high molecular weight polyphenols like proanthocyanins into lower molecular weight forms (Awika, 2003). A study on dark buckwheat flour reported no changes in antioxidant activity after extrusion at $170^{\circ} \mathrm{C}$ (Nayak et al., 2011). Another study showed a significant reduction in antioxidant activity for $60-68 \%$ and for TPC $46-60 \%$ in extrusion of barley flour (Altan, McCarthy, \& Maskan, 2008).
TPC content was determined in dried carrot, apple, pumpkin by-product flour, in rye and oat flour for crispbread production.

TPC in rye flour was $71.38 \pm 11.01$, in oats 24.64 \pm 1.68 , in by- product flour ranged from $132.44 \pm$ $11.88 \mathrm{mg}$ of $\mathrm{GAEg}^{-1} \mathrm{DW}$ in carrots, $160.23 \pm 6.89$ $\mathrm{mg}$ of $\mathrm{GAEg}^{-1} \mathrm{DW}$ in pumpkins, to $187.79 \pm 12.63$ mg of $\mathrm{GAEg}^{-1} \mathrm{DW}$ in apple by-product flour. Results about dried pumpkin TPC reported by Priecina and Karklina (2014) was 672.19 mg GAE $100 \mathrm{~g}^{-1}$ (Priecina \& Karklina, 2014). For carrots some authors show

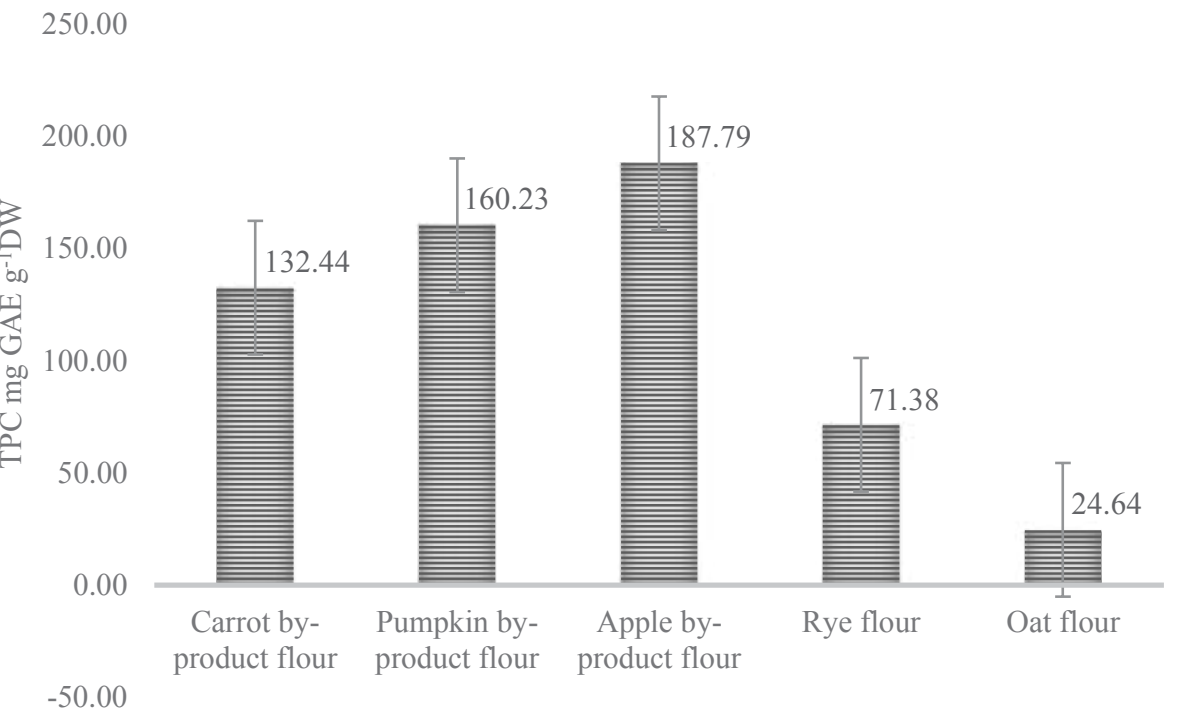

Figure 1. TPC content in rye flour, oat flour and by-product flour. 


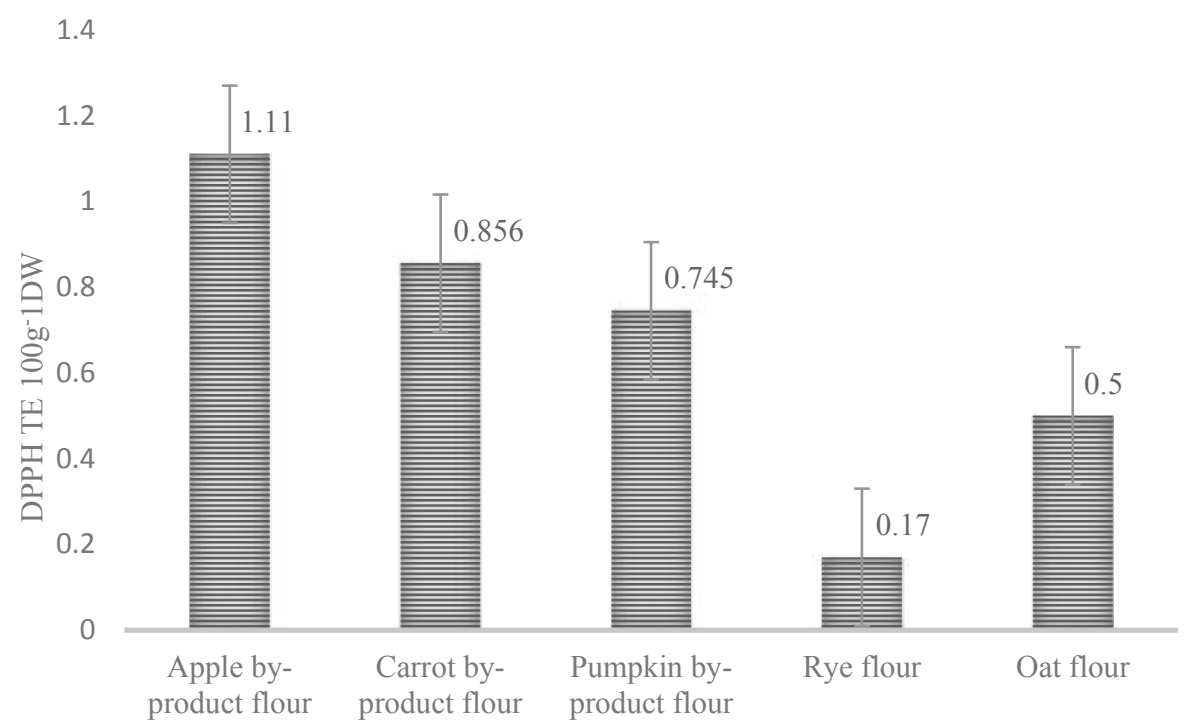

Figure 2. DPPH antioxidant activity in by-products, rye and oat flour.

results ranging from 331.00 to $366.00 \mathrm{mg} \mathrm{GAE} \mathrm{g}^{-1} \mathrm{DW}$ (Arscott \& Tanumihardjo, 2010). The difference in results is probably due to the application of different drying methods (Henriques, Guiné, \& Barroca, 2012) as phenolic compounds are heatliable and can break at the exposure to high temperatures.

The polarity of plant radical scavenging components is important factor defining extracts antioxidant activity.

The antioxidant activity of dried by-products, using DPPH assay, was $0.86 \pm 0.07 \mathrm{TE} 100 \mathrm{~g}^{-1} \mathrm{DW}$ in carrots, $0.75 \pm 0.02 \mathrm{TE} 100 \mathrm{~g}^{-1}$ in pumpkin and $1.11 \pm 0.05$ TE $100 \mathrm{~g}^{-1}$ DW DPPH antiradical activity in apple by- product. The DPPH is a stable free radical commonly used to determine the radical scavenging activity or antioxidant properties. The highest antioxidant activity was determined in apple by- product flour as apple by- products contain seeds rich in antioxidants and fatty acids in comparison with peel and bark (LeyvaCorral et al., 2016). Antioxidant activity is inhibited by many factors, mostly the composition of phenolic compounds in product, both phenolic compounds and carotenoids are strong in vitro antioxidants (Arscott \& Tanumihardjo, 2010). The phytochemicals present in apples such as carotenoids, vitamins, flavonoids, quercetin, catechin, phloridzin and

TPC and DPPH content in experimental samples for crispbread production

\begin{tabular}{|l|l|l|l|l|}
\hline \multirow{2}{*}{ Samples } & \multicolumn{2}{c|}{ DPPH, TE $100 \mathrm{~g}^{-1} \mathrm{DW}$} & \multicolumn{2}{c|}{ TPC, mg GAE·100 $\mathrm{g}^{-1} \mathrm{DW}$} \\
\cline { 2 - 5 } & \multicolumn{1}{|c|}{ before extrusion } & \multicolumn{1}{c|}{ after extrusion } & \multicolumn{1}{c|}{ before extrusion } & \multicolumn{1}{c|}{ after extrusion } \\
\hline Control crispbread & $0.24 \pm 0.06$ & $0.52 \pm 0.09$ & $62.03 \pm 0.15$ & $37.73 \pm 1.96$ \\
\hline ABF5 & $0.28 \pm 0.01$ & $0.44 \pm 0.03$ & $68.01 \pm 0.07$ & $78.57 \pm 1.23$ \\
\hline ABF10 & $0.32 \pm 0.04$ & $0.58 \pm 0.06$ & $74.00 \pm 0.05$ & $95.74 \pm 1.89$ \\
\hline ABF15 & $0.36 \pm 0.03$ & $0.78 \pm 0.07$ & $79.98 \pm 0.03$ & $156.98 \pm 2.80$ \\
\hline ABF20 & $0.41 \pm 0.02$ & $0.88 \pm 0.06$ & $85.96 \pm 0.08$ & $193.92 \pm 1.37$ \\
\hline CBF5 & $0.28 \pm 0.09$ & $0.54 \pm 0.08$ & $65.34 \pm 0.11$ & $122.08 \pm 3.96$ \\
\hline CBF10 & $0.29 \pm 0.07$ & $0.59 \pm 0.06$ & $68.64 \pm 0.11$ & $133.47 \pm 4.73$ \\
\hline CBF15 & $0.33 \pm 0.04$ & $0.83 \pm 0.05$ & $71.95 \pm 0.09$ & $160.70 \pm 2.96$ \\
\hline CBF20 & $0.36 \pm 0.05$ & $0.95 \pm 0.01$ & $75.25 \pm 0.05$ & $171.36 \pm 6.97$ \\
\hline PBF5 & $0.26 \pm 0.07$ & $0.78 \pm 0.10$ & $66.15 \pm 0.11$ & $177.73 \pm 5.09$ \\
\hline PBF10 & $0.29 \pm 0.02$ & $0.83 \pm 0.04$ & $70.27 \pm 0.13$ & $182.32 \pm 6.01$ \\
\hline PBF15 & $0.31 \pm 0.05$ & $0.88 \pm 0.05$ & $74.39 \pm 0.09$ & $188.28 \pm 6.57$ \\
\hline PBF20 & $0.34 \pm 0.08$ & $0.93 \pm 0.05$ & $78.51 \pm 0.12$ & $195.09 \pm 4.68$ \\
\hline
\end{tabular}




\section{Pearson's coefficients between TPC and antioxidant activity before and after extrusion}

\begin{tabular}{|l|c|c|c|}
\hline Correlation between group & Samples with apple BPF & Samples with carrot BPF & Samples with pumpkin BPF \\
\hline$T P C B E / T P C A E$ & 0.98 & 0.98 & 1.00 \\
\hline$T P C B E / D P P H B E$ & 1.00 & 1.00 & 1.00 \\
\hline$T P C A E / D P P H A E$ & 0.98 & 0.99 & 0.99 \\
\hline$D P P H B E / D P P H A E$ & 0.98 & 0.98 & 1.00 \\
\hline
\end{tabular}

$T P C B E$ - TPC before extrusion

$T P C A E$ - TPC after extrusion

$D P P H B E$ - DPPH before extrusion

$D P P H A E$ - DPPH after extrusion.

chlorogenic acid act as strong antioxidants (Shanmugam et al., 2017).

TPC and DPPH were determined for experimental samples with by-products before and after extrusion. Temperatures for extrusion zones according to developed technology at LTD Milzu were $125^{\circ} \mathrm{C} / 135$ ${ }^{\circ} \mathrm{C} / 145^{\circ} \mathrm{C}$, and water added to dry matter was $17 \%$. Results are shown in Table 3.

TPC content was determined before extrusion to predict the changes of TPC activity. In oat rye (control) crispbread TPC decreased after extrusion. Phenolic compounds are heatliable and can break at the exposure to high temperatures. Viscidi and others (2004) reported a significant loss of TPC during extrusion of oat cereals (Viscidi et al., 2004). In the sample from rye and oats blends (80:20), - control crispbread TPC content after extrusion decreased and varied from $62.03 \pm 0.15$ before extrusion to $37.73 \pm$ $1.96 \mathrm{mg} \mathrm{GAE} \cdot 100 \mathrm{~g}^{-1}$ after extrusion. Scientists Biel and others have reported losses of up to approximately $60 \%$ of phenolic compounds in extruded oat samples, compared to its respective raw sample (Biel et al., 2011). Extrusion increased TPC for all samples with added plant by- products (Table 3 ). In crispbreads with addition 5\% of pumpkin by-product TPC increased from $66.15 \pm 0.11$ to $177.73 \pm 5.09 \mathrm{mg} \mathrm{GAE} \cdot 100 \mathrm{~g}^{-1}$, addition $5 \%$ of apple by-product to control sample increased TPC from $68.01 \pm 0.07$ to $78.57 \pm 1.23 \mathrm{mg}$ $\mathrm{GAE} \cdot 100 \mathrm{~g}^{-1}$ after extrusion and addition $20 \%$ of ABF increased TPC from $85.96 \pm 0.08$ to $193.92 \pm 1.37 \mathrm{mg}$ $\mathrm{GAE} \cdot 100 \mathrm{~g}^{-1}$. Addition of $20 \%$ of PBF increased TPC from $78.51 \pm 0.12 \mathrm{mg} \mathrm{GAE} \cdot 100 \mathrm{~g}^{-1}$ before extrusion to $195.09 \pm 4.68 \mathrm{mg} \mathrm{GAE} \cdot 100 \mathrm{~g}^{-1}$ after extrusion.

This increase of polyphenol contents after heating is because of the high antioxidant activity after high temperatures during HTST process. The formation of phenolic compounds might be because of the availability of precursors of phenolic molecules by non-enzymatic interconversion (Camire, 2011). Another explanation for the higher TPC after heating is an increased formation of anthocyanin of browning compounds caused by the Maillard reaction at high temperatures (Basto et al., 2016).

The polarity of plant radical scavenging components is important factor defining extracts antioxidant activity.

The reduction in total phenolic content may be attributed either to the decomposition of phenolic compounds due to the high extrusion temperature. Addition of apple, pumpkin and carrot by-products increased the antioxidant activity in all samples as carotenoids and phenolic compounds are the predominant phytochemicals in all varieties of vegetables and fruits (Konrade et al., 2016).

For all crispbread samples correlation between groups of samples prior to extrusion and after extrusion was very strong $0.91<\mathrm{r}<0.99$, $(\mathrm{p}<0.05)$. To obtain higher TPC and DPPH, it is recommended to add $20 \%$ of by- products but further studies are necessary to understand how addition of by- products to cereal crispbreads change the texture, mouthfeel, colour and other physical and sensory features.

\section{Conclusions}

Addition of plant processing by-products increased TPC and the antioxidant activity in all samples of rye and oat-based crispbreads. Extrusion increased TPC content in samples with $20 \% \mathrm{ABF}$ to $193.92 \pm 1.37$ mg GAE $\cdot 100 \mathrm{~g}^{-1} \mathrm{DW}$, with $20 \% \mathrm{CBF}$ to $171.36 \pm 6.97$ $\mathrm{mg} \mathrm{GAE} \cdot 100 \mathrm{~g}^{-1} \mathrm{DW}, 20 \% \mathrm{PBF}$ to $195.09 \pm 4.68 \mathrm{mg}$ GAE $100 \mathrm{~g}^{-1}$ DW. Comparing the control sample, the antioxidant activity increased after extrusion of rye and oat-based sample when carrot and pumpkin by products were added, except 5\% apple BF decreased TPC to $0.44 \pm 0.03 \mathrm{mg}$ GAE $100 \mathrm{~g}^{-1} \mathrm{DW}$ probably of different chemical composition of ABF. The highest antioxidant activity was in samples with carrot by-products $\left(0.95 \pm 0.01 \mathrm{TE} 100 \mathrm{~g}^{-1} \mathrm{DW}\right)$, and pumpkin by products $0.93 \pm 0.05$ TE $100 \mathrm{~g}^{-1} \mathrm{DW} 20 \%$ addition respectively. Therefore, apple, carrot and pumpkin by-product flour is a good source of natural bioactive compounds and could be used as functional 
ingredients in production of crispbreads based on oat and rye flour.

\section{Acknowledgements}

In accordance

accordance with

1.2.1.1/16/A/004 competence centre Ltd. and the Central Finance and Contracting Agency, concluded on 11th of October 2016, the study is conducted by the Milzu Ltd. with support from the European Regional Development Fund within the framework of the project "Latvian Food Industry Competence Centre".

\section{References}

1. Altan, A., Mccarthy, K.L., \& Maskan, M. (2008). Evaluation of snack foods from barley - tomato pomace blends by extrusion processing, 84, 231-242. DOI: 10.1016/j.jfoodeng.2007.05.014.

2. Arscott, S.A., \& Tanumihardjo, S.A. (2010). Carrots of Many Phytochemicals Acting as a Functional Food. Comprehensive Reviews in Food Science and Food Safety, 9, 223-239.

3. Awika, J.M. (2003). Fruit and Cereal Bioactives: Sources, Chemistry, and Applications, 337-345.

4. Basto, G.J., Carvalho, C.W.P., Soares, A.G., Costa, H.T.G.B., Chávez, D.W.H., Godoy, R.L. de O., \& Pacheco, S. (2016). Physicochemical properties and carotenoid content of extruded and non-extruded corn and peach palm (Bactris gasipaes, Kunth). LWT - Food Science and Technology, 69, 312-318. DOI: 10.1016/j.lwt.2015.12.065.

5. Biel, W., Maciorowski, R., Bobko, K., \& Jaskowska, I. (2011). Chemical composition and energy value of dwarf oats grain. Italian Journal of Food Science, 23(2), 180-187.

6. Camire, M. (2011). Nutritional Changes during Extrusion Cooking. Advances in Food Extrusion Technology, 87-102. DOI: 10.1201/b11286-5.

7. Dar, A.H., Sharma, H.K., \& Kumar, N. (2014). Effect of extrusion temperature on the microstructure, textural and functional attributes of carrot pomace-based extrudates. Journal of Food Processing and Preservation, 38(1), 212-222. DOI: 10.1111/j.1745-4549.2012.00767.x.

8. Elleuch, M., Bedigian, D., Roiseux, O., Besbes, S., Blecker, C., \& Attia, H. (2011). Dietary fibre and fibre-rich by-products of food processing: Characterisation, technological functionality and commercial applications: A review. Food Chemistry, 124(2), 411-421. DOI: 10.1016/j.foodchem.2010.06.077.

9. Figuerola, F., \& Mar, A. (2005). Food Chemistry Fibre concentrates from apple pomace and citrus peel as potential fibre sources for food enrichment, 91, 395-401. DOI: 10.1016/j.foodchem.2004.04.036.

10. 10. Henriques, F., Guiné, R., \& Barroca, M.J. (2012). Chemical Properties of Pumpkin Dried by Different Methods, 7, 98-105.

11. Jiang, Q., Christen, S., Shigenaga, M.K., \& Ames, B.N. (2001). Tocopherol, the major form of vitamin E in the US diet, deserves more attention. American Journal of Clinical Nutrition, 74(6), 714-722.

12. Kaur, J., Kaur, A., \& Ahluwalia, P. (2014). Effect of pre-dehulling treatments on chemical composition, functional and pasting properties of whole oat flour. Carpathian Journal of Food Science and Technology, 6(2), 83-91.

13. Konrade, D., Klava, D., Sabovics, M., Kince, T., \& Kruma, Z. (2016). Plant by - products as source of natural antioxidants for production of crispbreads, 6(3), 3001.

14. Leyva-Corral, J., Quintero-Ramos, A., Camacho-Dávila, A., de Jesús Zazueta-Morales, J., AguilarPalazuelos, E., Ruiz-Gutiérrez, M.G., ... de Jesús Ruiz-Anchondo, T. (2016). Polyphenolic compound stability and antioxidant capacity of apple pomace in an extruded cereal. LWT - Food Science and Technology, 65, 228-236. DOI: 10.1016/J.LWT.2015.07.073.

15. Mala, S. (2016). Nutritional Composition and Antioxidant Activity of Pumpkin Wastes, 6(3), 336-344.

16. Mala, S., Sathiya Mala, K., \& EKurian, A. (2016). Nutritional Composition and Antioxidant Activity of Pumpkin Wastes. Ijpcbs 2016, 6(3), 336-344.

17. Nayak, B., Berrios, J.D.J., Powers, J.R., \& Tang, J. (2011). Effect of Extrusion on the Antioxidant Capacity and Color Attributes of Expanded Extrudates Prepared from Purple Potato and Yellow Pea Flour Mixes, 76(6), 874-884. DOI: 10.1111/j.1750-3841.2011.02279.x.

18. Paraman, I., Sharif, M.K., Supriyadi, S., \& Rizvi, S.S.H. (2015). Food and Bioproducts Processing Agrofood industry byproducts into value-added extruded foods. Food and Bioproducts Processing, 96, 78-85. DOI: 10.1016/j.fbp.2015.07.003.

19. Priecina, L., \& Karklina, D. (2014). Natural Antioxidant Changes in Fresh and Dried Spices and Vegetables, 3001(5), 492-496.

20. Shanmugam, S., Monis, S.A., Roy, N., Sruthi, D., Sangamithra, A., \& John, S.G. (2017). Effect of antioxidants and dietary fiber from apple and strawberries on value addition into mutton patties. Annals of the University Dunarea de Jos of Galati, Fascicle VI: Food Technology, 41(1), 95-105. 
21. Stenmark, Å., Jensen, C., Quested, T., \& Moates, G. (2016). Estimates of European food waste levels. IVLreport $C$ 186. DOI: 10.13140/RG.2.1.4658.4721.

22. Tomsone, L., \& Kruma, Z. (2017). Influence of harvest time on the phenolic content of Horseradish leaves. Baltic Conference on Food Science and Technology, 45-50. DOI: 10.22616/foodbalt.2017.019.

23. Turon, X., Venus, J., Arshadi, M., \& Koutinas, M. (2018). Food Waste and Byproduct Valorization through Bio-processing : Opportunities and Challenges, 9(4), 5774-5777.

24. Uddin, S., \& Ahmad, S. (1995). Dietary antioxidants protection against oxidative stress. Biochemical Education, 23(1), 2-7. DOI: 10.1016/0307-4412(94)00097-9.

25. Vaqué, L.G. (2015). Food Loss and Waste in the European Union : A New Challenge for the Food Law , 1979 (November 1979), 20-34.

26. Viscidi, K.A., Dougherty, M.P., Briggs, J., \& Camire, M.E. (2004). Complex phenolic compounds reduce lipid oxidation in extruded oat cereals. LWT - Food Science and Technology, 37(7), 789-796. DOI: 10.1016/J.LWT.2004.03.005. 